\title{
Susceptibility of biofilm forming Pseudomonas aeruginosa and Staphylococcus aureus to antibiotic-adjuvants
}

\author{
Mala Rajendran*, Ruby Celsia Arul Selvaraj, Hari Prasath Nagaiah, Keerthana Ravi Chandran and \\ Gopika Shri Janaki Raman \\ Department of Biotechnology, Mepco Schlenk Engineering College, Sivakasi-626005, Tamil Nadu, India. \\ Email: maalsindia@mepcoeng.ac.in
}

Received 24 November 2019; Received in revised form 11 February 2020; Accepted 18 April 2020

\begin{abstract}
Aims: The objective of the present study is to evaluate the possibility of reversing the resistance of pathogens to antibiotics using phytochemicals from plant extracts as antibiotic-adjuvant.

Methodology and results: Twenty-one plants were collected from Podhigai Hills, Tamil Nadu, India and tested in this study. The susceptibility of burn wound isolates (Pseudomonas aeruginosa and Staphylococcus aureus) to antibiotics and the adjuvant activity of the aqueous plant extracts were tested using well diffusion assay. The impact of the plant extracts on quorum sensing was assessed using Chromobacterium violaceum as the model organism. The antibiofilm activity of the adjuvant and antibiotics was determined by crystal violet assay. The isolates which were resistant to more than one class of antibiotics (aminoglycoside, cephalosporin, fluoroquinolone and penicillin) were designated as multidrug resistant bacteria. Combination of cefdinir-Citrullus colocynthis showed $17 \mathrm{~mm}$ inhibition zone which is greater than cefdinir $(0 \mathrm{~mm})$ against $P$. aeruginosa. The combination reduced quorum sensing with an inhibition zone of $30 \mathrm{~mm}$. The same combination reduced $96 \%$ and $95 \%$ of the biofilm formed by $P$. aeruginosa and $S$. aureus, respectively at $16 \mathrm{~h}$. Besides, cefdinir with Leucas aspera reduced quorum sensing with an inhibition zone of $28 \mathrm{~mm}$. The combination reduced $94 \%$ and $95 \%$ of biofilm formed by $P$. aeruginosa and $S$. aureus, respectively at $16 \mathrm{~h}$. The aqueous extract of $C$. colocynthis and $L$. aspera revealed the presence of flavonoids that possess adjuvant activity.

Conclusion, significance and impact of study: Cefdinir- $C$. colocynthis and cefdinir- $L$. aspera reversed the resistance of multi drug resistant bacteria to cefdinir. The flavonoids of $C$. colocynthis and $L$. aspera served as an adjuvant that potentiates the activity of cefdinir.
\end{abstract}

Keywords: Flavonoids, adjuvants, Citrullus colocynthis, Leucas aspera, quorum sensing

\section{INTRODUCTION}

Biofilm is a pattern of life adopted by bacteria on living and non-living solid surfaces. It is an association of bacteria encased inside self-assembled extracellular polymeric substances (EPS). EPS is composed of polysaccharides, proteins and DNA (Wolcott et al., 2010). Biofilm formation by bacteria in lungs causes cystic fibrosis, tuberculosis and pneumonia. Dental plague is caused by Streptococcus mutans. Approximately $60 \%$ of infectious diseases are caused by biofilm (Chen and Wen 2011). Biofilm is not only associated with tissue infections. It is the major hurdle to the success of medical devices like contact lens, prosthesis, heart valves, central venous catheter and urinary catheter (Percival and Kite 2007; Jamal et al., 2018). Biofilm formation occurs in two sequential stages namely, adhesion and maturation. Adhesion involves attachment to the substratum and maturation involves the multiplication and differentiation of the adhered cells. Maturation stage is determined by quorum sensing, the method of cell to cell communication in bacteria. GLASS (2018) by WHO reported that pathogens causing common infection are resistant to antibiotics. $\beta$-lactam class of antibiotics are widely used to control a broad range of infectious agents. Development of resistance to $\beta$-lactam antibiotics is due to the modification of target, presence of efflux pumps and production of $\beta$-lactamases. Exner et al. (2017) reported that five classes of $\beta$-lactamases are responsible for the alarming resistant to $\beta$-lactam class of antibiotics observed in health care unit. The key organisms resistant to antibiotics are Enterococcus faecium, Staphylococcus aureus, Klebsiella pneumoniae, Acinetobacter baumannii, Pseudomonas aeruginosa and Enterobacter spp. (ESKAPE). Quorum sensing facilitates bacteria to behave as multi-cellular organisms. Pathogens within the biofilm develop multiple strategies to resist antibiotics and evade immune system of the host. They prevent the entry of 
antibiotics into the biofilm through EPS (Francolini and Donelli, 2010). EPS neutralizes and dilutes the antimicrobial agents (Hall-Stoodley et al., 2004). Quorum sensing inhibitors are the major targets for controlling and eliminating biofilm, as they are the key regulators of biofilm formation, virulence and pathogenicity (Zhu and Mekalanos, 2003).

One possible way to counteract the effect of drug resistance is to discover new antibiotics. However, it takes approximately 20 years to commercialize a lead molecule. Many plant-derived compounds and metals like silver and zinc are used for potentiating the power of antibiotics. Many phytochemicals serve as an adjuvant that has no intrinsic antimicrobial action. Abreu et al. (2016) described the alarming increase in multi-drug resistance (MDR) among the pathogens that drives scientist to search for phytochemicals that serves as an adjuvant to antibiotics. Their study evaluated the adjuvant activity of phytochemicals from twenty-eight plants. Among the twenty-eight plants, Acacia dealbata, Pyrus communis, Prunus avium, Prunus domestica, Prunus persica, Centaurea nigra, Eupatorium cannabinum, Ficus carica and Buxus sempervirens potentiated the activity of ciprofloxacin, tetracycline and erythromycin (Abreu et al., 2016). The study identified betulinic acid and terpenoids as adjuvants. The investigation by Abreu et al. (2017) explored the role of isoflavonoids from Cytisus straitus as an adjuvant.

Exploiting adjuvants to sensitize the pathogens to already ineffective antibiotics is a cost effective and promising technology to combat antibiotic resistance threat. The effect of four adjuvants on the activity of novobiocin against Escherichia coli as model organism was reported earlier (Kalan and Wright, 2011). The study concluded with a hypothesis that, changes in the morphology of the cell leads to a change in the entry or exit of chemotherapeutic agents (Tegos et al., 2011). Adjuvants are broadly classified into class I and II (Zaheer et al., 2017). Class I works in association with antibiotics and class II improve the antimicrobial activity of the host. Class $I$ is subdivided into I.A and I.B by their different mechanism of action. Class I.A acts as an adjuvant by inactivating the enzymes that confer resistance to antibiotics, block the efflux pump or by altering their targets. Class I.B functions by evading intrinsic antimicrobial resistance mechanisms. Class I.B and II are still in pre-clinical trials (Worthington and Melander, 2013).

Plants are the richest source of therapeutic agents since ancient times, but no antibiotic has been produced from plants till now. It is due to the poor activity or toxicity of purified components. Minimum inhibitory concentration of phytochemicals against pathogens is high. Plants are constantly exposed to a variety of biotic and abiotic stress. They co-evolve strategies to combat the stress by producing a wide array of bioactive compounds. Even though no single potent antimicrobial agent was produced by plants, it produces structurally diverse compounds that act synergistically with antibiotics, that reverse the resistance of pathogens to antibiotics (Gonzalez-Lamothe et al., 2009). Plants also produce compounds that alter the physico-chemical properties of antibiotics by increasing their solubility, stability, availability and absorption. Efflux pump inhibitors produced by the plants prevent the efflux of antibiotics (Abreu et al., 2016). Clavulanic acid is a $\beta$-lactamases inhibitor with weak antibacterial activity, combination of clavulanic acid with amoxicillin remarkably improved the therapeutic efficiency of amoxicillin (Abreu et al., 2016). The present study evaluates the twenty-one plants extract for the production of antibiotic-adjuvants with the aim to reverse the resistance of pathogens to antibiotics by the combination of antibiotic-adjuvant and to evaluate their role as biofilm breakers.

\section{MATERIALS AND METHODS}

\section{Collection of clinical isolates}

The burn wound pathogens ( $S$. aureus and $P$. aeruginosa) used in the study were isolated from third degree burn wound. The swab of burn wound was collected as per ethical approval (Ref No: 75/E1/2016:dt. 22.08.2016) from the Government Hospital, Sivakasi, Tamil Nadu, India.

\section{Collection of plant samples for screening of antibiotic-adjuvant activity}

Twenty-one medicinal plants were collected from Sivakasi and Podhigai Hills, Coutrallam for screening of adjuvant

Table 1: Plants collected for screening of antibiotic-adjuvant activity in this study.

\begin{tabular}{|c|c|c|c|c|c|}
\hline 1) & Citrullus colocynthis $(\mathrm{F})$ & 8) & Allium cepa $(\mathrm{R})$ & 15) & Solanum procumbens $(\mathrm{L})$ \\
\hline 2) & Leucas aspera (L) & 9) & Zingiber officinale $(\mathrm{R})$ & 16) & Lawsonia inermis (L) \\
\hline 3) & Anisomeles malabarica $(\mathrm{L})$ & 10) & Ocimum tenuiflorum $(\mathrm{L})$ & 17) & Asystasia gangetica $(\mathrm{L})$ \\
\hline 4) & Microstachys chamaelea (L) & 11) & Ficus racemosa $(\mathrm{F})$ & 18) & Ocimum basilicum (L) \\
\hline 5) & Tribulus terrestris $(\mathrm{L})$ & 12) & Aegle marmelos $(\mathrm{L})$ & 19) & Catharanthus roseus (L) \\
\hline 6) & Kalanchoe pinnata (L) & 13) & Cynodon dactylon (L) & 20) & Morinda citrifolia $(\mathrm{L})$ \\
\hline 7) & Piper betle $(\mathrm{L})$ & 14) & Ricinus communis (L) & 21) & Indigofera tinctoria $(\mathrm{L})$ \\
\hline
\end{tabular}


(Table 1). The plants were shade dried. A total of $1 \mathrm{~g}$ of respective parts of the plants as mentioned in Table 1 were weighed and surface sterilized with ethanol. Aqueous extract of the plants were prepared with $20 \mathrm{~mL}$ of double distilled water. The extract was centrifuged at 10,000 rpm for $10 \mathrm{~min}$ and the supernatant was concentrated and dried in rotary evaporator at $50^{\circ} \mathrm{C}$ for $10 \mathrm{~h}$.

\section{Susceptibility of isolates to antibiotics and adjuvants by diffusion method}

Susceptibility of the clinical isolates was tested against amikacin-30 $\mu \mathrm{g}$ (aminoglycoside), ciprofloxacin-5 $\mathrm{\mu g}$ (fluoroquinolone) and cefdinir-5 $\mu \mathrm{g}$ (cephalosporin), amoxycillin-30 $\mathrm{\mu g}$ (penicillin) and amoxyclave-30 $\mu \mathrm{g}$ (penicillin). Optical density (OD) of the overnight grown culture was adjusted to 0.05 and swabbed on to Mueller Hinton agar. Wells of $8 \mathrm{~mm}$ diameter was punctured on the plates. Then, $100 \mu \mathrm{L}$ of plant extracts were added and the plates were incubated at $37{ }^{\circ} \mathrm{C}$ for $16 \mathrm{~h}$ (Smânia 1999). After incubation, the diameter of inhibition zone was measured in millimeters $(\mathrm{mm})$. The organisms were designated as resistant (R), susceptible (S) and intermittent (I) based on the inhibition zone as per the CLSI guidelines (CLSI, 2019). The plant extract was considered to possess adjuvant activity based on the diameter of inhibition zone of antibiotic and plant minus inhibition zone of antibiotic (Abreu et al., 2015). Based on result, the activity of plant extracts can be classified into three categories namely, indifferent $(<4 \mathrm{~mm})$, additive $(\geq 4$ $\mathrm{mm}$ ), potentiation ( $>6 \mathrm{~mm}$ ).

\section{Effect of antibiotic-adjuvants on quorum sensing}

Quorum sensing is an intercellular communication between bacteria through autoinducers. It is demonstrated using Chromobacterium violaceum strain (MTCC 2656). These bacteria specifically produce violet color pigmentation during quorum sensing. Lack of purple pigmentation from $C$. violaceum is an indicator of inhibition of quorum sensing. The OD of $C$. violaceum was adjusted to 0.1 and $100 \mu \mathrm{L}$ of culture was swabbed on agar plate. Well of $8 \mathrm{~mm}$ diameter was punctured and $100 \mu \mathrm{L}$ of respective plant extracts were added. The plates were then incubated at $37{ }^{\circ} \mathrm{C}$ for $16 \mathrm{~h}$. Violet pigmentation in the plates indicate the quorum sensing. The zone of clearance of violet colour indicates the quenching of quorum sensing. The diameter of zone of clearance is proportion to the ability of the test compound to inhibit quorum sensing (Fuqua et al., 1994). Cefdinir was used as the antibiotic control for assessing quorum sensing.

\section{Effect of antibiotic-adjuvants on biofilm and planktonic cells}

Biofilm formation was evaluated by crystal violet assay in a sterile 24 well plate. $2 \mathrm{~mL}$ of nutrient broth and $200 \mu \mathrm{L}$ of culture $(0.05 \mathrm{OD})$ were added to all wells. Each treatment was replicated thrice. The plate was incubated for $16 \mathrm{~h}$ and $50 \mathrm{~h}$ as an adherence period. After incubation, the medium was drained off and $2 \mathrm{~mL}$ of fresh broth along with $200 \mu \mathrm{L}$ of antibiotic-adjuvants (1:5) were added. A control well was maintained with $200 \mu \mathrm{L}$ of phosphate buffered saline. After incubation for $24 \mathrm{~h}$, the planktonic cells were collected in a separate tube. The OD of the planktonic cells was read at $600 \mathrm{~nm}$. The adhered biofilm was stained with crystal violet. The dye was solubilized with $1 \%$ glacial acetic acid. The OD of the samples was read at $660 \mathrm{~nm}$ for the quantification of biofilm (Walker and Horswill, 2012). Reduction in biofilm and planktonic cells were assessed by comparing with the control at $16 \mathrm{~h}$ and $50 \mathrm{~h}$, respectively using the formula:

$$
\begin{aligned}
& \text { Reduction }(\%)= \\
& \text { (Control OD - Test OD) /Control OD } \times 100
\end{aligned}
$$

\section{Phytochemical analysis of plants}

Aqueous extract of plants $(1 \mathrm{~g} / 20 \mathrm{~mL}$ of double distilled water) were qualitatively analyzed for the presence of flavonoids, alkaloids and tannins (Reynolds et al., 1998).

\section{Test for flavonoids}

The presence of flavonoids was confirmed by adding 5 drops of $1 \mathrm{~N}$ sodium hydroxide to $3 \mathrm{~mL}$ of the plant extract. Formation of yellow color that disappears on the addition of $0.1 \mathrm{~N}$ hydrochloric acid confirms the presence of flavonoids.

\section{Test for alkaloids}

The presence of alkaloids was tested by Mayer's test. To $5 \mathrm{~mL}$ of the plant extract, 3 drops of concentrated sulphuric acid was added followed by the addition of 5 drops of Mayer's reagent. Formation of orange colored precipitate is an indication of positive test.

\section{Test for phenols}

Five drops of neutralized ferric chloride were added to 5 $\mathrm{mL}$ of the plant extract. Formation of green color is an indication of positive test.

\section{Statistical analysis}

All experiments were repeated thrice. The data represented in the graph are the mean of three values with standard error of the mean. All the calculations and graphs were drawn using in GraphPad Prism 5.

\section{RESULTS AND DISCUSSION}

\section{Sensitivity of isolates to antimicrobial agents}

\section{Antibiotics}

The sensitivity of the isolates to amikacin 
Table 2: Sensitivity of the bacteria isolates from burn wound to antibiotics.

\begin{tabular}{|c|c|c|c|c|c|}
\hline \multirow[b]{2}{*}{ Bacteria } & \multicolumn{5}{|c|}{ Inhibition zone (mm) } \\
\hline & 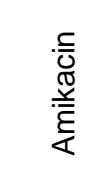 & 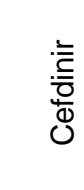 & 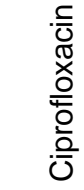 & 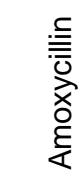 & 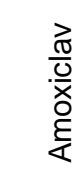 \\
\hline S. aureus & $\begin{array}{l}10.0 \\
\pm 0.5\end{array}$ & $\begin{array}{l}5.0 \\
\pm 0.1\end{array}$ & $\begin{array}{l}9.0 \\
\pm 0.2\end{array}$ & $\begin{array}{l}8.0 \\
\pm 0.1\end{array}$ & $\begin{array}{l}10.0 \\
\pm 0.1\end{array}$ \\
\hline $\begin{array}{l}P . \\
\text { aeruginosa }\end{array}$ & $\begin{array}{l}7.0 \\
\pm 0.4\end{array}$ & $\begin{array}{l}0.0 \\
\pm 0.0\end{array}$ & $\begin{array}{l}2.0 \\
\pm 0.0\end{array}$ & $\begin{array}{l}5.0 \\
\pm 0.2\end{array}$ & $\begin{array}{l}8.0 \\
\pm 0.1\end{array}$ \\
\hline
\end{tabular}

(aminoglycoside), cefdinir (cephalosporin), ciprofloxacin (fluroquinolone), amoxycillin (penicillin) and amoxiclav (penicillin and $\beta$-lactam inhibitor) are represented in Table 2. The inhibition zone exhibited by all antibiotics against $S$. aureus and $P$. aeruginosa were $\leq 10 \mathrm{~mm}$. The isolates were resistant to more than one class of antibiotic (aminoglycoside, cephalosporin, fluoroquinolone and penicillin) and hence they were interpretted as MDR bacteria. From Table 2, the inhibition zone exhibited by cefdinir was $5 \mathrm{~mm}$ and $0 \mathrm{~mm}$ against $S$. aureus and $P$. aeruginosa, repectively, which show $S$. aureus and $P$. aeruginosa are highly resistant to cefdinir. Cefdinir is a $\beta$ lactam antibiotic from cephalosporin class. $\beta$-lactam antibiotics are widely used to control infection. Bacteria develop resistance to $\beta$-lactam antibiotics by the synthesis of $\beta$-lactamase which is a threat to human being (Wright, 2016).

\section{Adjuvants}

Antimicrobial activity of the twenty-one plants collected were tested against two MDR organisms and the results are depicted in Figure 1a and Figure $1 \mathrm{~b}$ representing $S$. aureus and $P$. aeruginosa, respectively. As the inhibition zone obtained for all plant extracts were less than $3 \mathrm{~mm}$, it was considered to be insignificant for antibacterial activity (Abreu et al., 2017). To be used as an adjuvant, phytochemicals need not to possess antibacterial activity. But phytochemicals need to interact together with different compounds to enhance their activity mutually. They can improve the efficiency of antibiotics or reverse the resistance developed by pathogens due to efflux pump or $\beta$-lactamases (Chevalier et al., 2004).

\section{Antibiotic-adjuvants}

Among the antibiotics used for evaluating the sensitivity of bacteria, the inhibition zone exhibited by cefdinir was very low with $5 \mathrm{~mm}$ and $0 \mathrm{~mm}$ against $P$. aeruginosa and $S$. aureus, respectively (Table 2 ). So, the adjuvant activity of plant extracts was tested with cefdinir only. The effect of adjuvant from plant extracts and their combination with cefdinir against $S$. aureus and $P$. aeruginosa are

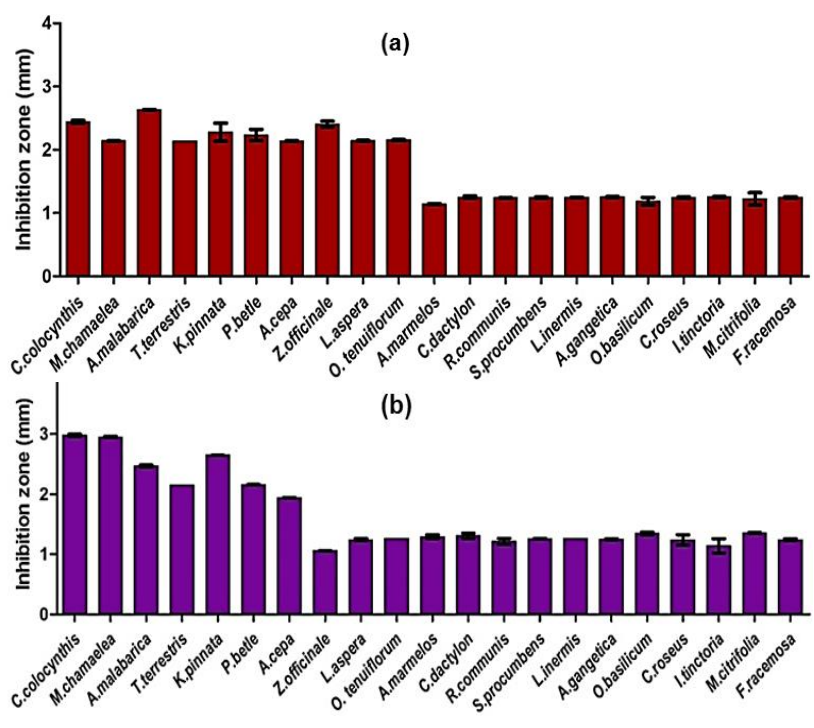

Figure 1: Sensitivity of bacteria (a) $S$. aureus (b) $P$. aeruginosa to various plant extracts.

represented in Figure $2 \mathrm{a}$ and Figure $2 \mathrm{~b}$, respectively. Aqueous extract from six plants namely $C$. colocynthis, $L$. aspera, K. pinnata, A. malabarica, M. chamaelea and $T$. terrestris exhibited high adjuvant property when compared to others. Inhibition zone exhibited by cefdinir, $C$. colocynthis and cefdinir-C. colocynthis against $P$. aeruginosa were $0 \mathrm{~mm}, 3 \mathrm{~mm}$ and $17 \mathrm{~mm}$, respectively. On the other hand, the inhibition zone exhibited by cefdinir, C. colocynthis and cefdinir-C. colocynthis against $S$. aureus were $5 \mathrm{~mm}, 2.5 \mathrm{~mm}$ and $17 \mathrm{~mm}$, respectively. The adjuvant activity of $L$. aspera was high next to $C$. colocynthis with an inhibition zone of $16 \mathrm{~mm}$ against $P$. aeruginosa and $S$. aureus. The other plants such as $M$. chamaela, $A$. malabarica and $K$. pinnata exhibited an inhibition zone of $16.8 \mathrm{~mm}, 15.6 \mathrm{~mm}$ and 15.5 $\mathrm{mm}$ respectively against $P$. aeruginosa and $S$. aureus.

Similar observation of phytochemicals potentiating the activity of antibiotics is supported by Abreu et al. (2017) and Gill et al. (2015). Abreu et al. (2017) reported that the compounds from Cytisus striatus was not active in in vitro tests when assessed alone. Different compounds can interact together and enhance their activity mutually. In the present study, plant extracts alone exhibited no antibacterial activity. But when combined with cefdinir, the activity was significantly enhanced. The results clearly demonstrated the potency of plant extracts in improving the effectiveness and reversing the resistance of antibiotics. Therefore, to identify the chemical nature of phytochemicals present in the extract, qualitative screening was done, and the results are shown in Table 3.

\section{Effect of antibiotic-adjuvants on quorum sensing}

Quorum sensing is one of the important virulence factors for biofilm formation. Antimicrobial agents (antibiotics, 


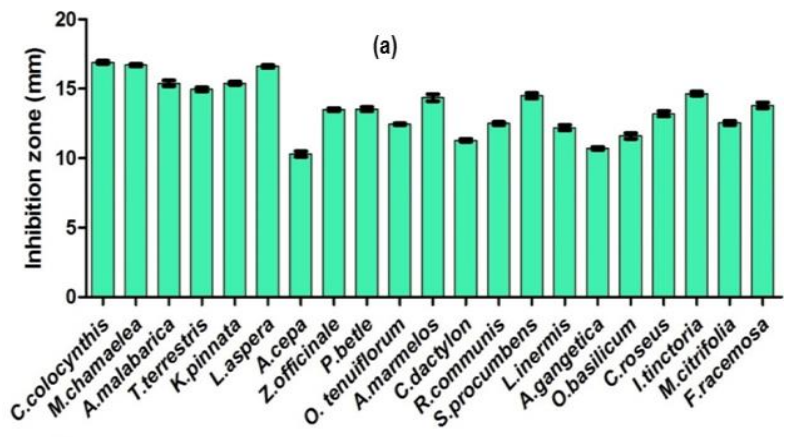

(b)

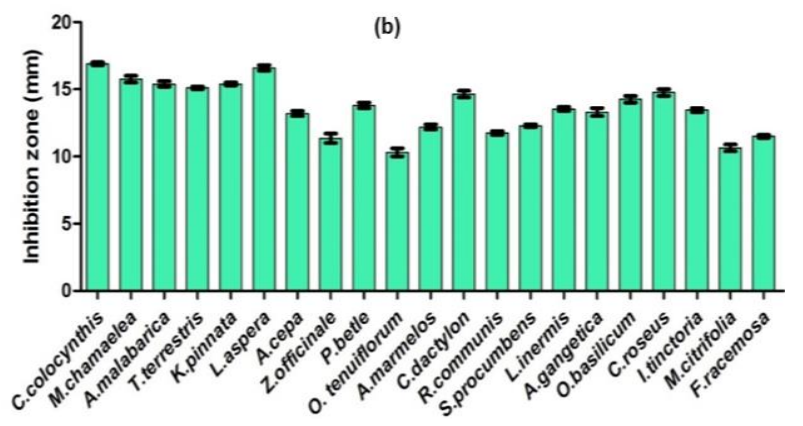

Figure 2: Sensitivity of bacteria (a) $S$. aureus (b) $P$ aeruginosa against cefdinir-plant extracts.

adjuvants and antibiotic-adjuvants) were assessed for their quorum quenching activity using $C$. violaceum (Zhu et al., 2011). Among the 21 different plant extracts, only four plants (C. colocynthis, L. aspera, A. malabarica and $M$. chamaelea) exhibited quorum quenching activity and the results are represented in Figure $3 \mathrm{a}$ and Figure $3 \mathrm{~b}$. The plants which lack quorum quenching activity had no zone of clearance and the results are represented in Figure 3c. Among the four quorum quenching plants, $C$. colocynthis and $L$. aspera were found to have a clearance zone of $14 \mathrm{~mm}$ and $13 \mathrm{~mm}$, respectively when used alone. The same adjuvants in combination with cefdinir showed an increased inhibition zone to $30 \mathrm{~mm}$ and 28 $\mathrm{mm}$, respectively. The results were supported by the observations of Bacha et al. (2016). Their study demonstrated that tannins and flavonoids are responsible for quorum quenching activity. Thus, the antibioticadjuvants have significant quorum quenching activity than existing antibiotics. Among the 4 plants which were tested for quorum quenching activity, $C$. colocynthis and $L$. aspera are widely distributed than other plants in Podhigai hills. So, they were used for biofilm and planktonic cells reduction in present study.

\section{Effect of antibiotic-adjuvant on biofilm and planktonic cell reduction}

Biofilm formation in tissues and medical devices starts from $8 \mathrm{~h}$ to $12 \mathrm{~h}$. Later it fully matures in $48 \mathrm{~h}$. Hence in the present study, the effect of antibiotic-adjuvant on the biofilm forming ability of $S$. aureus and $P$. aeruginosa were evaluated at $16 \mathrm{~h}$ and $50 \mathrm{~h}$ by crystal violet assay and the results are depicted in Figures 4 and 5 .
Table 3: Phytochemical analysis of the aqueous extract of plants.

\begin{tabular}{lccc}
\hline Plants & Flavonoids & Alkaloids & Phenols \\
\hline C. colocynthis & + & - & + \\
L. aspera & + & - & + \\
K. pinnata & + & + & - \\
A. malabarica & + & + & + \\
M. chamaelea & + & - & - \\
T. terrestris & + & - & + \\
\hline
\end{tabular}

(+): Presence; (-): Absence

C. colocynthis reduced $55 \%$ of biofilm of $P$. aeruginosa at $16 \mathrm{~h}$ and $43 \%$ at $50 \mathrm{~h}$. Cefdinir inhibited $57 \%$ of biofilm at $16 \mathrm{~h}$ and $50 \%$ at $50 \mathrm{~h}$. But the combination of cefdinir-C. colocynthis inhibited $96 \%$ and $90 \%$ at $16 \mathrm{~h}$ and $50 \mathrm{~h}$, respectively. L. aspera reduced $44 \%$ and $36 \%$ of biofilm formed by $P$. aeruginosa at $16 \mathrm{~h}$ and $50 \mathrm{~h}$, respectively. When cefdinir was used with $L$. aspera extract, $94 \%$ and $88 \%$ of biofilm formed by $P$. aeruginosa at $16 \mathrm{~h}$ and $50 \mathrm{~h}$, respectively were reduced. The study demonstrated that the biofilm reduction was higher at $16 \mathrm{~h}$ than 50 h. C. colocynthis reduced $51 \%$ and $50 \%$ of biofilm formed by $S$. aureus at $16 \mathrm{~h}$ and $50 \mathrm{~h}$, respectively. Cefdinir inhibited $55 \%$ of $S$. aureus biofilm at $16 \mathrm{~h}$ and
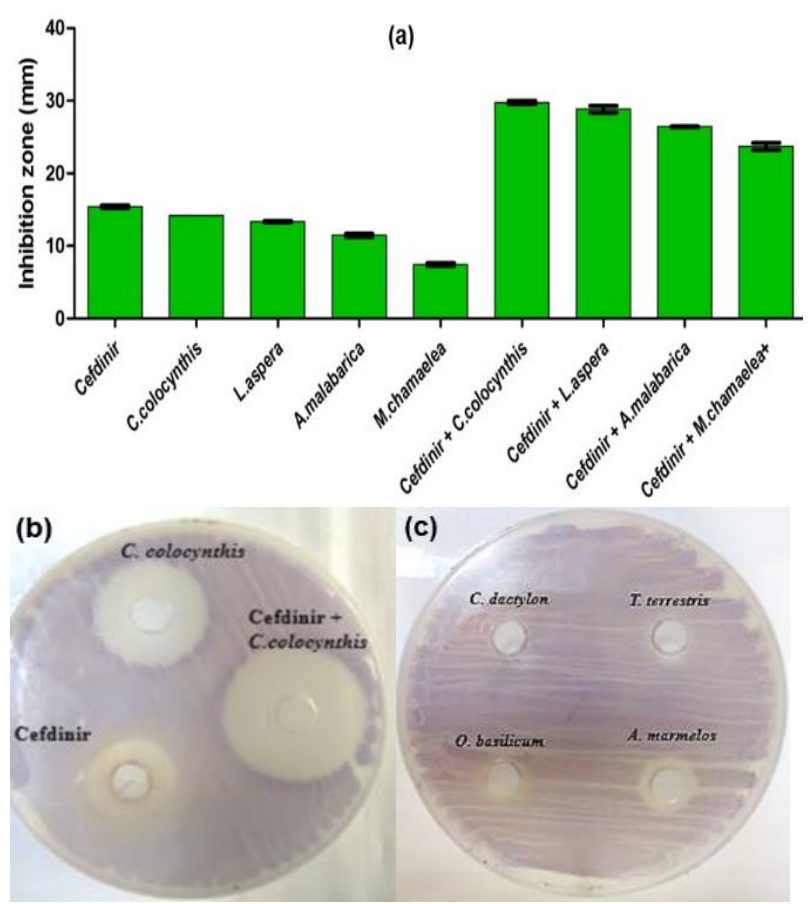

Figure 3: Influence of cefdinir-plant extracts on quorum quenching of $C$. violaceum. (a) Inhibition zone exhibited by cefdinir-plant extracts (b) Plate showing quorum quenching by cefdinir and $C$. colocynthis plant extract (c) Plant extracts with no quorum quenching activity. 


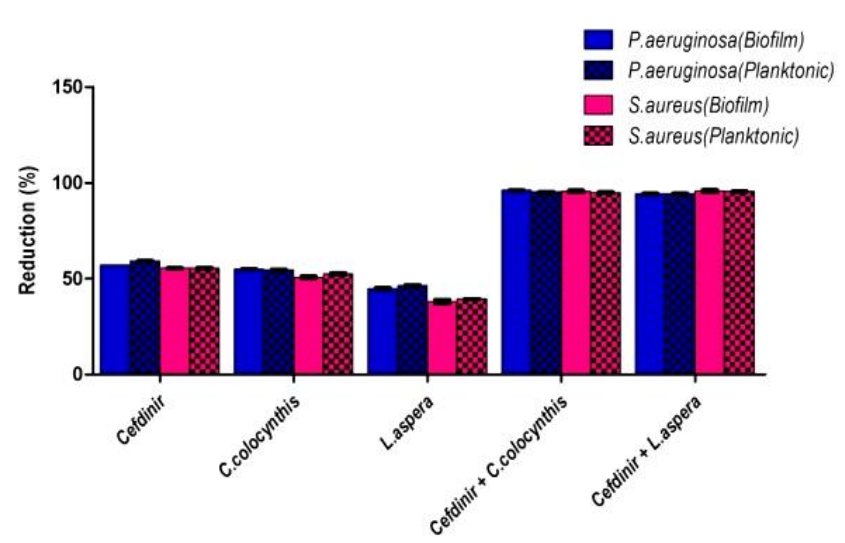

Figure 4: Influence of antibiotic-adjuvant on biofilm and planktonic cells reduction in $16 \mathrm{~h}$.

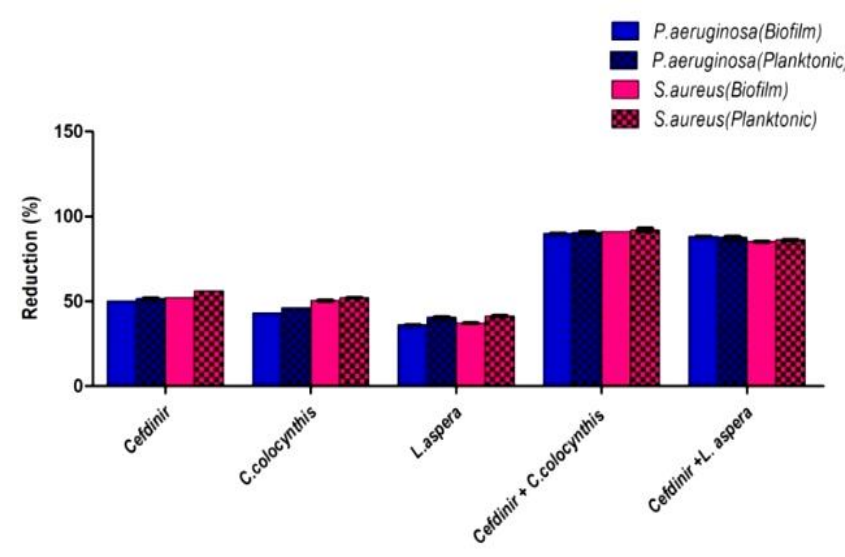

Figure 5: Influence of antibiotic-adjuvant on biofilm and planktonic cells reduction in $50 \mathrm{~h}$.

$52 \%$ at $50 \mathrm{~h}$. But the combination of cefdinir- $C$. colocynthis inhibited S. aureus biofilm $95 \%$ and $91 \%$ at $16 \mathrm{~h}$ and $50 \mathrm{~h}$, respectively. Leucas aspera reduced $37 \%$ and $37 \%$ of biofilm formed by $S$. aureus at $16 \mathrm{~h}$ and $50 \mathrm{~h}$, respectively. When cefdinir was used with $L$. aspera extract, $95 \%$ and $85 \%$ of biofilm formed by $S$. aureus was reduced at $16 \mathrm{~h}$ and $50 \mathrm{~h}$, respectively.

The results confirmed that the bioactive compounds in the plant functions as an adjuvant by improving the efficiency of cefdinir (Grassi et al., 2017). The plant might have compounds that inhibited $\beta$-lactamase or efflux pump inhibitors that are responsible for the resistance of pathogens to cefdinir. The antibiotic-adjuvant potentiated the antibiotic and reversed the resistance (Wright, 2016). Bacterial biofilm are resistant to antibiotics and are comparatively susceptible to antibiotic-adjuvant combination. There is a possibility of phytochemicals increasing the permeability of bacterial cell to antibiotics that result in reduction in biofilm and planktonic cells. The data represented in Figure $2 \mathrm{a}$ and $2 \mathrm{~b}$ also supported the reduction in the bacterial load. The plant extracts that exhibited quorum quenching activity which reduced the multiplication of bacteria. Biofilm formation is favored by the extensive communication among bacteria through quorum sensing. The antibiotic-adjuvant reduced the planktonic cells and biofilm by targeting multiple points. Quorum sensing is one of the virulent factors that facilitate the formation of biofilm. Blocking quorum sensing and increased permeability of antibiotic has resulted in the reduction of biofilm and planktonic cells.

\section{Phytochemical screening of plants}

The phytochemicals present in the selected plants are represented in Table 3 . The table clearly reveals that flavonoids are present in all the four plants which play a promising role as an antibiotic adjuvant. Alkaloids are present in the aqueous extract of $K$. pinnata and $A$. malabarica. The role of flavonoids as an adjuvant was reported by Abreu et al. (2017). In the present study, it is also confirmed that flavonoids are present in aqueous fraction that served as an adjuvant. Further studies are needed to purify and characterize the specific flavonoids from the plant extracts that possess adjuvant activity to antibiotics.

\section{CONCLUSION}

The study demonstrates the aqueous plant extracts of $C$. colocynthis and $L$. aspera in combination with cefdinir possessed ability to reverse the resistance of $S$. aureus and $P$. aeruginosa to cefdinir and potent antibiofilm property towards clinical isolates of $S$. aureus and $P$. aeruginosa. Therefore, the present study reveals the phytochemicals from $C$. colocynthis and $L$. aspera plant extracts can be used as an antibiotic adjuvant to improve the antibacterial and antibiofilm activities of cefdinir against $S$. aureus and $P$. aeruginosa.

\section{ACKNOWLEDGEMENTS}

This work was financially assisted by DST Nano Mission (SR/NM/NS-01/2015(G)), Delhi, India and Tamil Nadu State Council for Science and Technology, Tamil Nadu, India.

\section{REFERENCES}

Abreu, A. C., Coqueiro, A., Sultan, A. R., Lemmens,N., Kim, H. K., Verpoorte, R., van Wamel, W. J. B., Simoes, M. and Choi, Y. H. (2017). Looking to nature for a new concept in antimicrobial treatments: Isoflavonoids from Cytisus striatus as antibiotic adjuvants against MRSA. Scientific Reports 7, 3777.

Abreu, A. C., Paulet, D., Coqueiro, A., Malheiro, J., Borges, A., Saavedra, M. J., Choi, Y. H. and Simões, M. (2016). Antibiotic adjuvants from Buxus sempervirens to promote effective treatment of drugresistant Staphylococcus aureus biofilms. RSC Advances 6, 95000-95009.

Abreu, A. C., Serra, S. C., Borges, A., Saavedra, M. J., McBain, A. J. Salgado, A. J. and Simoes, M. 
(2015). Combinatorial activity of flavonoids with antibiotics against drug-resistant Staphylococcus aureus. Microbial Drug Resistance 21, 600-609.

Bacha, K., Tariku, Y., Gebreyesus, F., Zerihun, S., Mohammed, A., Weiland-Brauer, N. Schmitz, R. A. and Mulat, M. (2016). Antimicrobial and anti-quorum sensing activities of selected medicinal plants of Ethiopia: Implication for development of potent antimicrobial agents. BMC Microbiology 16, 139.

Chen, L. and Wen, Y. M. (2011). The role of bacterial biofilm in persistent infections and control strategies. International Journal of Oral Science 3, 66-73.

Chevalier, J., Bredin, J., Mahamoud, A., Mallea, M., Barbe, J. and Pages, J. M. (2004). Inhibitors of antibiotic efflux in resistant Enterobacter aerogenes and Klebsiella pneumoniae strains. Antimicrobial Agents and Chemotherapy 48, 1043-1046.

Clinical Laboratory Standards Institute (CLSI) (2019). Performance Standards for Antimicrobial Susceptibility Testing. 29th ed. CLSI supplement M 100. Wayne, PA.

Exner, M., Bhattacharya, S., Christiansen, B., Gebel, J., Goroncy-Bermes, P., Hartemann, P., Heeg, P., Ilschner, C., Kramer, A., Larson, E., Merkens, W., Mielke, M., Oltmanns, P., Ross, B., Rotter, M., Schmithausen, R. M., Sonntag, H. G. and Trautmann, M. (2017). Antibiotic resistance: What is so special about multidrug-resistant Gram-negative bacteria? GMS Hygiene and Infection Control 12, Doc05.

Francolini, I. and Donelli, G. (2010). Prevention and control of biofilm-based medical-device-related infections. FEMS Immunology and Medical Microbiology 59, 227-238.

Fuqua, W. C., Winans, S. C. and Greenberg, E. P. (1994). Quorum sensing in bacteria: The LuxR-LuxI family of cell density-responsive transcriptional regulators. Journal of Bacteriology 176, 269-275.

Gill, E. E., Franco, O. L. and Hancock, R. E. (2015). Antibiotic adjuvants: Diverse strategies for controlling drug-resistant pathogens. Chemical Biology and Drug Design 85, 56-78.

Global Antimicrobial Resistance Surveillance System (GLASS) (2018). Global Antimicrobial Resistance Surveillance System (GLASS) Report: Early Implementation 2017-2018. World Health Organization, Geneva.

Gonzalez-Lamothe, R., Mitchell, G., Gattuso, M., Diarra, M. S., Malouin, F. and Bouarab, K. (2009). Plant antimicrobial agents and their effects on plant and human pathogens. International Journal of Molecular Science 10, 3400-3419.

Grassi, L., Maisetta, G., Esin, S. and Batoni, G. (2017). Combination strategies to enhance the efficacy of antimicrobial peptides against bacterial biofilms. Frontiers in Microbiology 8, 2409.

Hall-Stoodley, L., Costerton, J. W. and Stoodley, P. (2004). Bacterial biofilms: From the natural environment to infectious diseases. Nature Reviews in Microbiology 2, 95-108.
Jamal, M., Ahmad, W., Andleeb, S., Jalil, F., Imran, M., Nawaz, M. A., Hussain, T., Ali, M., Rafiq, M. and Kamil, M. A. (2018). Bacterial biofilm and associated infections. Journal of Chinese Medical Association 81, 7-11.

Kalan, L. and Wright, G. D. (2011). Antibiotic adjuvants: Multicomponent anti-infective strategies. Expert Revies in Molecular Medicine 13, e5.

Percival, S. L. and Kite, P. (2007). Intravascular catheters and biofilm control. Journal of Vascular Access 8, 69-80.

Reynolds, V., Plumptre, A. J., Greenham, J. and Harborne, J. (1998). Condensed tannins and sugars in the diet of chimpanzees (Pan troglodytes schweinfurthii) in the Budongo Forest, Uganda. Oecologia 115, 331-336.

Smânia, A., Monache, F. D., Smânia, E. F. A. and Cuneo, R.S. (1999). Antibacterial activity of steroidal compounds isolated from Ganoderma applanatum (Pers.) Pat. (Aphyllophoromycetideae) fruit body. International Journal of Medicinal Mushrooms, 1, 325330.

Tegos, G. P., Haynes, M., Strouse, J. J., Khan, M. M., Bologa, C. G., Oprea, T. I. and Sklar, L. A. (2011). Microbial efflux pump inhibition: Tactics and strategies. Current Pharmaceutical Design 17, 12911302.

Walker, J. N. and Horswill, A. R. (2012). A coverslipbased technique for evaluating Staphylococcus aureus biofilm formation on human plasma. Frontiers in Cellular and Infection Microbiology 2, 00039.

Wolcott, R. D., Rhoads, D. D. Bennett, M. E. Wolcott, B. M. Gogokhia, L. Costerton, J. W. and Dowd, S. E. (2010). Chronic wounds and the medical biofilm paradigm. Journal of Wound Care 19(2), 45-53.

Worthington, R. J. and Melander, C. (2013). Combination approaches to combat multidrugresistant bacteria. Trends in Biotechnology 31, 177184.

Wright, G. D. (2016). Antibiotic adjuvants: Rescuing antibiotics from resistance. Trends in Microbiology 24(11) 862-871.

Zaheer, Z, Rahman, S. U., Zaheer, I., Younas, T., Abbas, G. and Zaheer, T. (2017). Antimicrobial adjuvants - an innovative strategy for handling antimicrobial resistance displayed by microbes. Journal of Bacteriology and Mycology 5(4), 352-354.

Zhu, H., He, C. C. and Chu, Q. H. (2011). Inhibition of quorum sensing in Chromobacterium violaceum by pigments extracted from Auricularia auricular. Letters in Applied Microbiology 52, 269-274.

Zhu, J. and Mekalanos, J. J. (2003). Quorum sensingdependent biofilms enhance colonization in Vibrio cholerae. Developmental Cell 5, 647-656. 